\title{
Hepatic Lymphomas Post Renal Transplantation May Signify Worse Disease Behavior: Analysis of Data from 26 International Studies
}

\author{
Hossein Khedmat ${ }^{* 1}$, Saeed Taheri ${ }^{2}$ \\ 1. The Internist Research Center; Department of Internal Medicine; Baqiyatallah University of Medical Sciences, Tehran, Iran \\ 2. Dr Taheri Medical Research Group, Tehran, Iran
}

\begin{abstract}
Introduction: Hepatic involvement by posttransplant lymphoproliferative disorders (PTLD) is an important but rarely investigated issue. In the current study, we aimed to pool data of cases of PTLD localization in liver (L-PTLD) among renal allograft recipients from different series to find new perspectives on the disease.
\end{abstract}

Methods: We conducted a comprehensive search for the available data through PubMed and Google Scholar for reports of PTLD localization in the liver and surrounding lymph nodes in renal allograft recipients. Data of 232 cases from 26 international studies have been pooled and reanalyzed.

Results: Patients with L-PTLD were significantly more likely to be of male gender $(\mathrm{P}=0.02)$. Death due to PTLD was higher in L-PTLD patients $(\mathrm{P}=0.06)$. Disseminated PTLD, based on our definition, was significantly more prevalent in L-PTLD than in none-liver-PTLD (NL-PTLD) $(\mathrm{P}<0.001)$; the same finding was noted with multi-organ involvement which was significantly higher in L-PTLD $(\mathrm{P}<0.001)$. L-PTLD was significantly more likely to complicate heart $(\mathrm{P}=0.03)$, bone marrow $(\mathrm{P}=0.002)$, spleen $(\mathrm{P}=0.01)$, and kidney allograft involvement $(\mathrm{P}=0.04)$.

Conclusion We conclude that renal transplant patients exhibiting liver localization for PTLD should be carefully followed for multi-organ involvement. Most notably, bone marrow biopsy should be considered, and evaluations for renal allograft, heart and spleen localization for PTLD should be executed. Due to the unfavorable characters of liver localization by PTLD in renal recipients, we propose higher levels of evaluations and follow up for these patients. Prospective studies with larger patient populations are needed to confirm our results.

* Corresponding Author; Prof. Hossein Khedmat, The Internist Research Center, Baqiyatallah University of Medical Sciences, Mollasadra st, Vanak sq, Tehran, Iran; E mail: Khedmat.h@gmail.com
Keywords: Kidney Transplantation; Liver Localization; Lymphoproliferative Disorders

\section{The authors declared no conflict of interest}

\section{Introduction}

Malignancies occurring post renal transplantation are important complications which seriously threat patient and graft survival [1-3]. Cancers complicating renal allograft recipients are considered as the third reason of death in this patient population, after cardiovascular diseases and infections [4]. Post transplant lymphoproliferative disease (PTLD) is a well-known and one of the most prevalent malignancies in transplant recipients and an important cause of morbidity and mortality in these patients. PTLD represents a wide spectrum of abnormal lymphoid proliferations taking place in the setting of ineffective T-cell function due to immunosuppression after organ transplantation. Viral infection most notable for EpsteinBarr virus (EBV), type of organ transplantation, type and potency of immunosuppressive agents employed, and some demographic features of the organ recipients have all been associated with a higher incidence or outcome of PTLD in transplant era [5-9]. As mentioned above, the type of organ transplanted is a key factor in determining the incidence and features of PTLD. The incidence of PTLD is reportedly lowest in renal transplant recipients $(0.8-2 \%)[10,11]$. Moreover; it is generally considered that PTLD has a better outcome in renal allograft recipients compared to some other types of organ transplant patients such as heart graft recipients [12].

Complications of specific organs in various types of organ transplantation are of outmost relevance. Knowing susceptible organs for getting involved by PTLD in renal allograft recipients, we would be able to target our preventive endeavors more accurately, and to minimize morbidity and mortality in renal transplant population who develop PTLD in their disease course. On the other hand, revealing factors which play major roles in 
inducing or preventing more aggressive forms of the disease or non-favorable histopathological features of PTLD lesion will also help us enhance our treatment strategies and improve outcomes. The overall number of liver involvement by PTLD in renal graft recipients is very limited and its cases are hidden in series related to single- or multi-center reports. In fact, until now, no study has focused on liver localization of PTLD in renal recipients; and to the extent of our knowledge, this is the first attempt on the issue. In the current study, we aimed to pool data of cases of PTLD localization in liver of renal recipients from different series to find new perspectives on the disease.

\section{Methods}

Approach to the study: We conducted a comprehensive search for the available data through PubMed and Google Scholar for reports of PTLD localization in liver and surrounding lymph nodes in renal allograft recipients. Search terms used were "lymphoproliferative disorders + renal transplantation + liver", "lymphoproliferative disorders + kidney transplantation + hepatic localization", "lymphoproliferative disorder + renal transplantation + liver localization", "lymphoproliferative disorders + kidney transplantation + liver". In cases where we were not able to obtain the full text of the article, e-mails were sent to the correspondent authors requesting the article. Of the full texts obtained, we only included studies in which data on each patient was presented separately. To minimize selection bias, we only included studies reporting their series of patients from single- or multicenter populations, and studies with any specific selection criterion were excluded from the analysis. Control patients were renal recipients in whom PTLD localization organ was not the liver. A standard questionnaire was developed to collect data from different published studies. The time between transplantation and PTLD onset was defined as the period between the graft and the first sign(s) of PTLD or diagnosis, depending on the study's approach.

Study population: Twenty-six internationally-published studies [13-38] were found that met our criteria. A total of 232 renal recipients with a documented PTLD site were included in the analysis; of whom $44(19 \%)$ had liver PTLD (L-PTLD) and the remaining 188 (81\%) patients had developed non-liver PTLD (NL-PTLD). EBV status was documented in 157 (67.7\%) patients, of whom 113 (72\%) were reportedly positive. Because of different methodologies employed in the published studies enrolled into this study, some of our measures were not available for all the patients. So we tried to standardize the data. We recorded disseminated PTLD when it was reported by the study authors or if at least three different organs were involved by the PTLD (different lymph node areas were excluded from analysis due to lack of knowledge on how to categorize; unless they were concomitant with other organs involvement; or other authors specifically presented them as having disseminated disease). According to the above mentioned, data on disseminated PTLD was available for 167 patients (72\%; 65 unreported data). Multi-organ involvement, defined as involvement of more than one organ (the second organ could be a lymphatic region), was reported in 216 patients $(93.1 \%$; 16 unavailable data).

At PTLD onset, all patients were under immunosuppressive regimens consisting of varying combinations of azathioprine, prednisone, cyclosporine, mycophenolate mofetil, ATG/ALG and OKT3. A rather uniform approach was used to manage most of the included PTLD renal recipients. On diagnosis of PTLD, the first step in almost all reports was to decrease or discontinue immunosuppressive therapy; various regimens of chemotherapy with or without surgical interventions were also used for some patients.

Response to treatment: We defined response to treatment as any favorable change both in PTLD measures as well as the patient's clinical condition. Data on response to treatment was reported for 114 patients (49.1\%), of whom $71(62.3 \%)$ responded to treatment and had a remission episode. To create a common standard across the studies, we defined a "remission" episode as when a patient was alive 24 months after PTLD onset (because all reported cases meeting this criterion had at least one confirmed remission episode). "No remission" was defined as when a patient died within the first month after PTLD onset (because there were no patients dying at the first post-transplant month that were reported to have any remission episode). According to these criteria, data on remission was available for 171 patients $(73.7 \%)$, of whom $98(57.3 \%)$ had at least one response to treatment, irrespective of their future disease course. Data on mortality was available for 219 patients (94.4\%), of whom 133 (60.7\%) died. We defined death due to PTLD when the authors stated it, death was within 6 months after onset, or death was reported to be due to PTLD treatment complications. Based on these criteria, 82 patients (61.7\% of reported deaths) died due to PTLD.

Statistical analysis: SPSS v.13.0 software was used for data analyses. Statistical comparisons between patient subgroups were performed using chi-square and Fisher's exact tests for proportions, and the Student's t-test for continuous data. Survival analysis was done with life tables, Kaplan-Meier method and log-rank test. Multivariate linear regression was used to detect independent association of various factors with the time interval between transplantation and PTLD onset. A 
Table 1: Characteristics of renal transplant recipients and their PTLD lesions, respecting hepatic localization of the PTLD

\begin{tabular}{|c|c|c|c|c|}
\hline Variables & L-PTLD & NL-PTLD & P value & Available data \\
\hline Age (years; mean \pm SD) & $37.4 \pm 18.3$ & $40.5 \pm 17.1$ & 0.3 & 230 \\
\hline Gender male (\%) & $32(78)$ & $101(57.7)$ & $0.02^{*}$ & 216 \\
\hline Time to PTLD development (months; mean \pm SD) & $53.8 \pm 53.7$ & $59.3 \pm 56.8$ & 0.6 & 219 \\
\hline Early onset (within first 12 months post TX) & $12(30.8)$ & $47(26.9)$ & 0.7 & 214 \\
\hline Time from diagnosis to death (months; mean $\pm \mathrm{SD}$ ) & $11.3 \pm 20$ & $13.1 \pm 20.3$ & 0.7 & 113 \\
\hline Basic immunosuppression protocol & & & 0.5 & 126 \\
\hline Cyclosporine and Prednisolone & $1(5.3)$ & $2(1.9)$ & & \\
\hline Azathioprine & $14(73.7)$ & $80(74.8)$ & & \\
\hline Mycophenolate Mofetil & $1(5.3)$ & $15(14)$ & & \\
\hline FK-506 & $3(15.8)$ & $10(9.3)$ & & \\
\hline Use of antibody induction & $14(70)$ & $71(67)$ & 1.0 & 126 \\
\hline Multi organ involvement ${ }^{+}$ & $35(81.4)$ & $54(31.2)$ & $<0.001^{*}$ & 216 \\
\hline Disseminated PTLD $^{+}$ & $16(48.5)$ & $16(11.9)$ & $<0.001^{*}$ & 167 \\
\hline Proportion of B cell & $18(81.8)$ & $62(91.2)$ & 0.3 & 90 \\
\hline Morphology & & & 0.8 & 135 \\
\hline Early lesion (Plasmacytic hyperplasia) & $1(0.7)$ & $3(2.2)$ & & \\
\hline Polymorphic B cell lymphoma & $12(8.9)$ & $41(38.3)$ & & \\
\hline Monomorphic PTLD & $14(10.4)$ & $54(40)$ & & \\
\hline Hodgkin lymphoma & $1(0.7)$ & $9(6.7)$ & & \\
\hline EBV positive & $22(78.6)$ & $91(70.5)$ & 0.5 & 157 \\
\hline Remission episode & $14(43)$ & $84(60.4)$ & 0.1 & 171 \\
\hline
\end{tabular}

Data presented as number (\%); PTLD: posttransplant lymphoproliferative disorders; L-PTLD: PTLD localization in the liver; NL-PTLD: non-liver PTLD

* Statistically significant

$\dagger$ According to the criteria defined in the methods section

P-value of 0.05 was taken as the threshold for significance and of 0.1 was defined as relevance level.

\section{Results}

Overall, 232 cases of PTLD in renal allograft recipients were included. There were $133(61.6 \%)$ male and 83 (38.4\%) female patients (16 unreported data). Mean age at onset was $39.9 \pm 17.3$ years. The mean interval between transplantation and the onset of PTLD was 58.3 \pm 56.1 months and the mean follow up time after onset of PTLD was $23.9 \pm 32.4$ months.

Characteristics of PTLD patients with and without liver involvement are summarized in Table-1. Chi-square test showed that patients with L-PTLD were significantly more likely to be of male gender $(\mathrm{P}=0.02)$. L-PTLD patients were comparable to NL-PTLD kidney recipients in their age $(\mathrm{P}=0.3)$, immunosuppressive drug basis $(\mathrm{P}=0.5)$, history of induction therapy $(\mathrm{P}=1.0)$, lymphoma cell type $(\mathrm{P}=0.3)$, histopathological features of PTLD lesions $(\mathrm{P}=0.8)$, time from transplantation to $\mathrm{PTLD}$ diagnosis $(\mathrm{P}=0.6)$, remission rates $(\mathrm{P}=0.1)$, and mortality rate $(\mathrm{P}=0.3)$. However, death due to $\mathrm{PTLD}$ was higher in L-PTLD patients $(\mathrm{P}=0.06)$. Disseminated PTLD, based on our definition, was significantly more prevalent in L-PTLD than in NL-PTLD $(\mathrm{P}<0.001)$; the same finding was achieved reporting multi-organ involvement which was significantly higher in L-PTLD $(\mathrm{P}<0.001)$.

Table-2 compares liver to NL-PTLD with respect to other organs involved. L-PTLD was significantly more likely to complicate heart $(\mathrm{P}=0.03)$, bone marrow $(\mathrm{P}=0.002)$, spleen $(\mathrm{P}=0.01)$, and kidney allograft involvement $(\mathrm{P}=0.04)$.

At the last follow up, 133 patients were dead. Using death by any cause as the outcome, log-rank test did not show any difference between the two groups in survival ( $\mathrm{P}=0.4$; Figure-1). Renal recipients with L-PTLD had a relevantly poorer PTLD-related outcome when only death due to PTLD (based on our definition) was used 
Table 2: Frequency of the concomitant organs involved by PTLD in renal transplant recipients with and without hepatic involvement by the malignancy

\begin{tabular}{lllll}
\hline Involved organs & L-PTLD & NL-PTLD & P value & Available data \\
\hline Orbital & 0 & $1(0.7)$ & 1.0 & 193 \\
Skeleton & 0 & $5(3.3)$ & 0.4 & 192 \\
Stomach & $1(2.7)$ & $9(5.9)$ & 0.7 & 189 \\
Genitalia & $2(5)$ & $3(2)$ & 0.3 & 191 \\
CNS & $3(6.8)$ & $24(15.3)$ & 0.2 & 201 \\
Spleen & $8(20)$ & $9(6.1)$ & $0.01^{*}$ & 188 \\
Colon & $4(10)$ & $5(3.3)$ & 0.09 & 193 \\
Small intestine & $3(8.3)$ & $27(17.5)$ & 0.2 & 190 \\
Kidney & $13(33.3)$ & $26(17.1)$ & $0.04^{*}$ & 191 \\
Respiratory system & $7(18.9)$ & $15(10.4)$ & 0.2 & 181 \\
Bone marrow & $8(20)$ & $6(4)$ & $0.002^{*}$ & 190 \\
Skin & $2(4.9)$ & $20(13.2)$ & 0.2 & 133 \\
Heart & $3(10.7)$ & $1(1 \%)$ & $0.03^{*}$ & \\
\hline
\end{tabular}

Data presented as number (\%); PTLD: posttransplant lymphoproliferative disorders; L-PTLD: PTLD localization in the liver; NL-PTLD: non-liver PTLD

* statistically significant

as the outcome and other deaths were censored $(\mathrm{P}=0.1$, Figure-2). One- and five-year survival rates for L-PTLD patients were $47 \%$ and $29 \%$, respectively, compared to $57 \%$ and $31 \%$, respectively, for NL-PTLD controls.

\section{Discussion}

PTLD is a life threatening and not such a rare complication of transplantation with a very wide spectrum of clinical findings ranging from a focal and limited disease to a disseminated and rapidly progressive disorder. The frequency has been reported to range very widely depending on the organ transplanted and the type, dosage and duration of immunosuppressive agents employed for preventing rejection episodes, with a reported incidence range of less than $1 \%$ to $30 \%$ in different transplant populations $[10,39,40]$. In renal allograft recipients, the incidence of PTLD is reported to range from $0.7 \%$ to $2.6 \%$ in different series $[18,41,42]$. The outcome of PTLD in renal recipients has also been implicated to be better than other types of organ recipients, although the reported survival of renal recipients with PTLD in different series was quite variable. Several factors can play major roles in these disparities among which the histopathological features of the PTLD lesions, the type and number of organs involved by the cancer, therapeutic approaches employed for managing the disease, and physical status of the patients can be relevant. To clarify factors most likely to influence PTLD behavior, we need to study a large number of patients to analyze the potential contributing factors. Nevertheless, due to the very limited number of patients who provide information on each of the aforementioned, our knowledge on these would be essentially limited. So, in our PTLD questionnaire we tried to gather data of individual patients reported in different published series to make the largest possible population to investigate the impact of these factors. In a previous study, we analyzed hepatic graft involvement by PTLD in liver recipients [9] and in the present study; we explore the same organ complication by PTLD in renal allograft recipients.

In the current study, we found that renal allograft recipients with liver PTLD localization are more likely to represent a disseminated disease, with a relatively poorer outcome, although the difference did not reach the significance level in the latter case. However, adding this to the higher rate of multi-organ PTLD in L-PTLD, this study shows a relatively more ominous disease in renal graft recipients whose liver has been complicated by PTLD compared to other disease localizations. In our previous study on liver transplant patients [9], consistent with the current study, we found that disseminated disease is significantly higher in patients representing hepatic localization for the PTLD; however, in that study, no outcome difference has been implicated. Moreover, liver recipients with hepatic PTLD were significantly older at the time of transplantation and had a shorter time to PTLD development, observations which have not been repeated in the current study on kidney recipients. Nuckols et al [43] have also found that 
Figure 1: Survival curves of renal graft recipients with and without hepatic PTLD (outcome: death irresepctive of the reason)

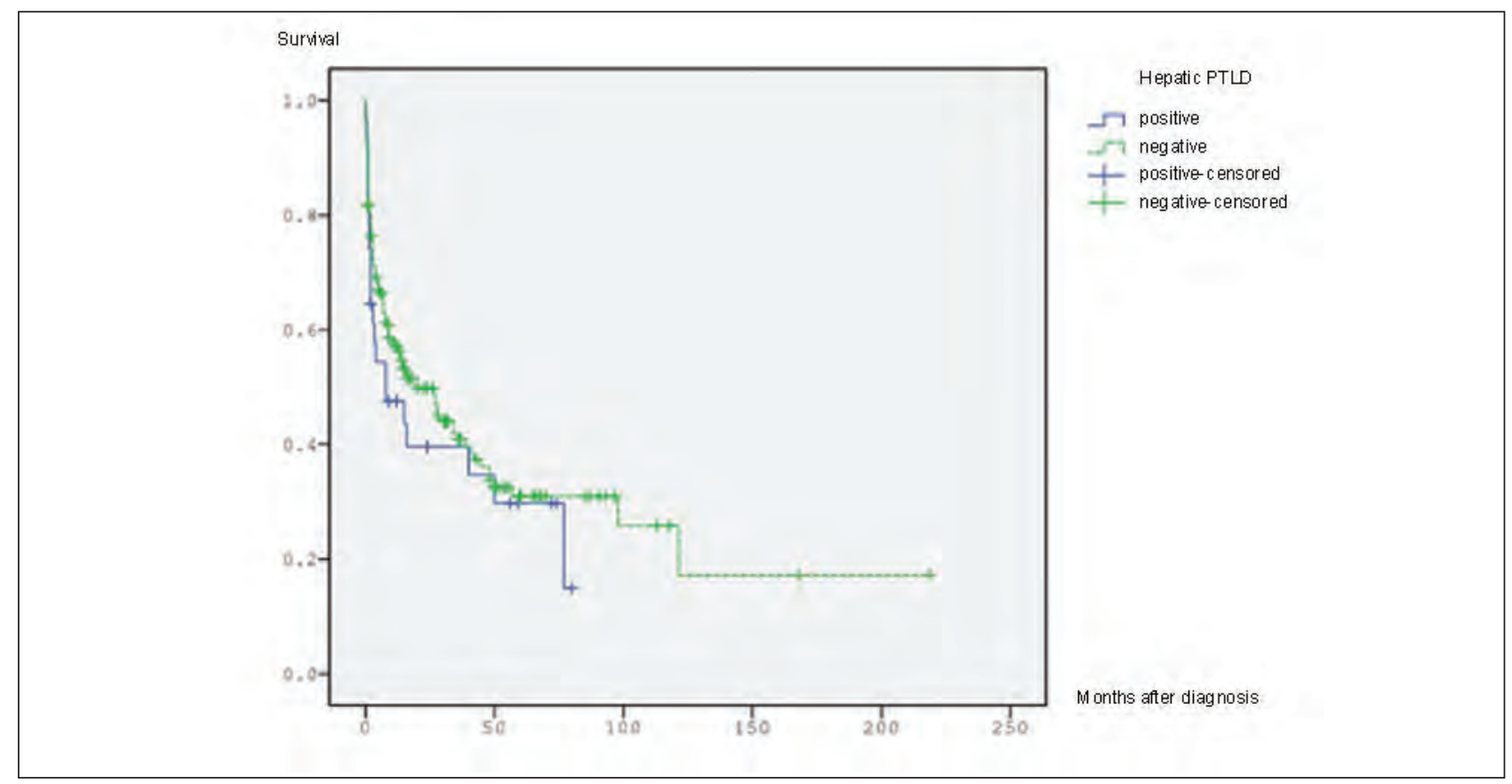

almost all of their hepatic PTLD liver transplant cases were of early onset. Put together, these findings may indicate that this is a special character of liver PTLD in liver recipients. Moreover, Nuckols et al [43] reported a three times larger share of males in hepatic PTLD in liver recipients. In the current study, we also found that male renal recipients were significantly more likely to develop hepatic PTLD, although in our previous report on liver recipients, we did not find any gender disparity regarding liver involvement by the PTLD [9]. An interesting similar finding of the current study to our previous report on liver transplantation is heart and bone marrow involvement. In both, renal and liver recipients whose livers have been involved by PTLD, there were significantly higher tendencies for heart and bone marrow involvement by the PTLD, simultaneous to the liver disease. This finding is of outmost relevance; suggesting that liver involvement by lymphomas can be associated with the same complication in bone marrow and/or heart. These findings more intensively alert us to assess the heart and bone marrow of patients who have already developed lymphomas within their liver. Kidney allograft and spleen were also more likely to be complicated by the PTLD simultaneously with a liver involvement in our series of renal allograft recipients, a finding that seems to be special for kidney recipients, since it was not reported in liver transplant patients.

This study has several limitations. Firstly, this is a retrospective review of studies that used different methodologies to report on PTLD. Secondly, the enrolled data gathered from those studies were not originally presented in the same way, and it was not possible to pool them without some manipulations. So, we had to standardize data to be able to compare them with each other. Standardization of data was not easy, and some people may not fully agree with us on the standardization methods employed in the current study.

\section{Conclusion}

We conclude that renal transplant patients exhibiting liver localization for PTLD should be carefully evaluated for multi-organ involvement. Most notably, bone marrow biopsy should be considered, and evaluations for renal allograft, heart and spleen localization for PTLD should be executed. Due to the unfavorable characters of liver localization by PTLD in renal recipients, we propose higher levels of evaluations and follow up for these patients. Prospective studies with large patient populations are needed to confirm our results.

\section{References}

1. Penn I, Hammond W, Brettschneider L, Starzl TE. Malignant lymphomas in transplantation patents. Transplant Proc. 1969 Mar;1(1):106-12.

2. Penn I. De novo cancers in organ allograft recipients. Curr Opin Organ Transplant. 1998;3:188-96. 
Figure 2: Survival curves of renal graft recipients with and without hepatic PTLD (outcome: death due to PTLD)

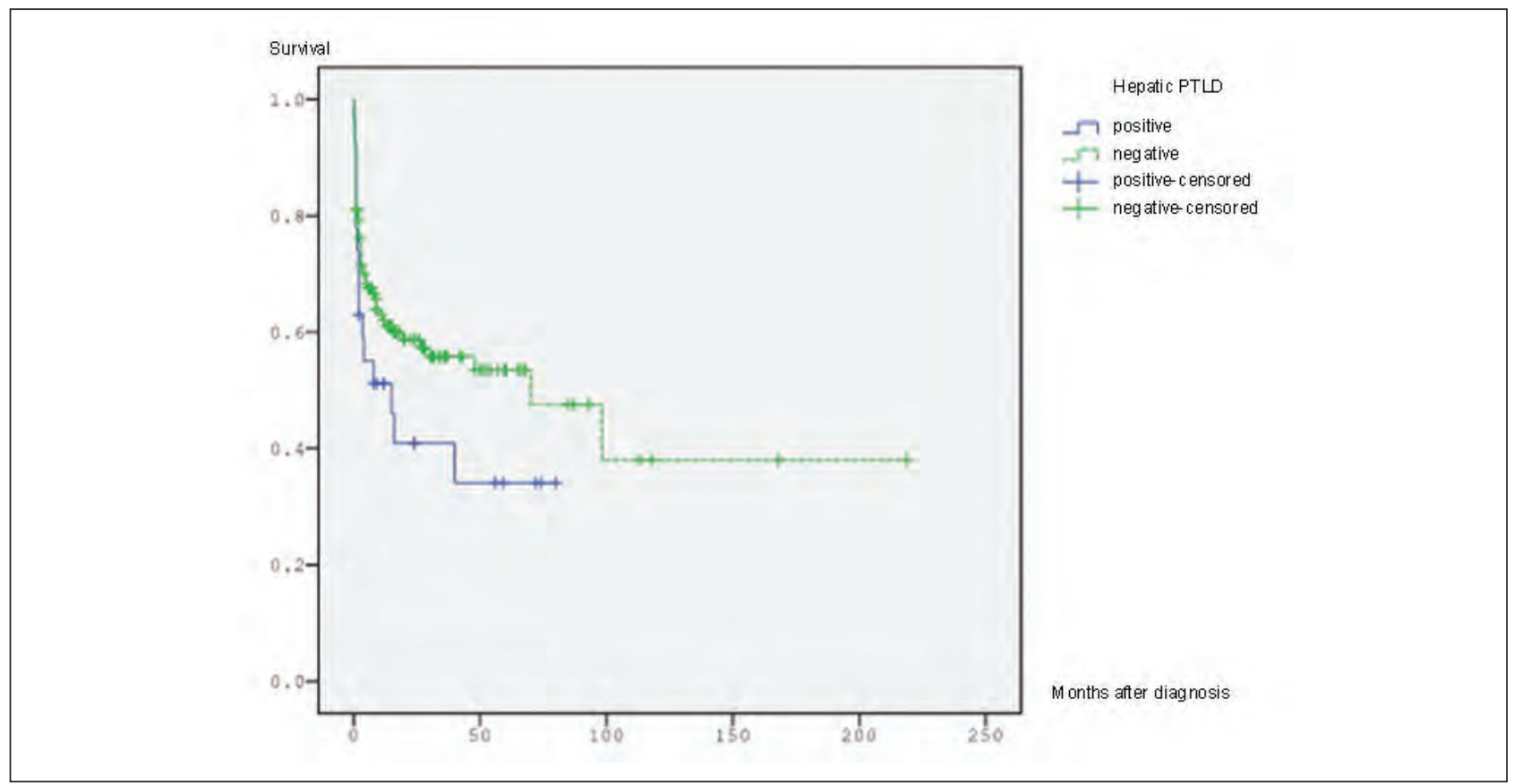

3. Khedmat H, Taheri S. Characteristics and prognosis of post-transplant lymphoproliferative disorders within renal allograft: Report from the PTLD.Int. Survey. Ann Transplant. 2010;15(3):80-6.

4. Ojo AO, Hanson JA, Wolfe RA, Leichtman AB, Agodoa LY, Port FK. Long-term survival in renal transplant recipients with graft function. Kidney Int. 2000 Jan;57(1):307-13.

5. Izadi M, Taheri S. Significance of in situ hybridization results for EBV-encoded RNA in post-transplantation lymphoproliferative disorder setting: Report from the PTLD.Int Survey. Ann Transplant. 2010 Dec 22;15(4):102-9.

6. Izadi M, Taheri S. Features, predictors and prognosis of lymphoproliferative disorders post-liver transplantation regarding disease presentation time: Report from the PTLD.Int. survey. Ann Transplant. 2011 Mar 23;16(1):3947.

7. Khedmat H, Taheri S. Post-Transplantation Lymphoproliferative disorders localizing in the adenotonsillar region: Report from the PTLD.Int survey. Ann Transplant. 2011 Mar 23;16(1):109-16.

8. Khedmat H, Taheri S. Early versus late outset of lymphoproliferative disorders post-heart and lung transplantation: The PTLD.Int Survey. Hematol Oncol Stem Cell Ther. 2011;4(1):10-6.
9. Izadi M, Fazel M, Saadat SH, Taheri S. Hepatic involvement by lymphoproliferative disorders post liver transplantation: PTLD.Int. Survey. Hepatol Int. 2011 Mar 30

10. Hanto DW, Frizzera G, Gajl-Peczalska KJ, Simmons RL. Epstein-Barr virus, immunodeficiency, and B cell lymphoproliferation. Transplantation. 1985;39(5):46172.

11. Opelz G, Henderson R. Incidence of non-Hodgkin lymphoma in kidney and heart transplant recipients. Lancet. 1993 Dec;342(8886-8887):1514-6.

12. Khedmat H, Taheri S. Heart Involvement by Post Transplantation Lymphoproliferative Disorders: Report from the PTLD. Int Survey. Exp Clin Transplant. 2011 Aug;9(4):258-64.

13. Mamzer-Bruneel MF, Lomé C, Morelon E, Levy V, Bourquelot P, Jacobs F, Gessain A, Mac Intyre E, Brousse N, Kreis H, Hermine O. Durable remission after aggressive chemotherapy for very late post-kidney transplant lymphoproliferation: A report of 16 cases observed in a single center. J Clin Oncol. 2000 Nov $1 ; 18(21): 3622-32$.

14. Jain M, Badwal S, Pandey R, Srivastava A, Sharma RK, Gupta RK. Post-transplant lymphoproliferative disorders after live donor renal transplantation. Clin Transplant. 2005 Oct;19(5):668-73. 
15. Pourfarziani V, Taheri S, Lessan-Pezeshki M, Nourbala MH, Simforoosh N, Nemati E, Makhdoomi K, Ghafari A, Ahmadpour P, Nafar M, Einollahi B. Lymphoma after living donor kidney transplantation: an Iranian multicenter experience. Int Urol Nephrol. 2008;40(4):1089-94.

16. Hanto DW, Frizzera G, Purtilo DT, Sakamoto K, Sullivan JL, Saemundsen AK, Klein G, Simmons RL, Najarian JS. Clinical spectrum of lymphoproliferative disorders in renal transplant recipients and evidence for the role of Epstein-Barr virus. Cancer Res. 1981 Nov;41(11 Pt 1): 4253-61.

17. Hoshida Y, Li T, Dong Z, Tomita Y, Yamauchi A, Hanai J, Aozasa K. Lymphoproliferative disorders in renal transplant patients in Japan. Int J Cancer. 2001 Mar;91(6):869-75.

18. Cockfield SM, Preiksaitis JK Jewell LD, Parfrey NA. Post-transplant lymphoproliferative disorder in renal allograft recipients. Clinical experience and risk factor analysis in a single center. Transplantation. 1993 Jul;56(1):88-96.

19. Jain A, Nalesnik M, Reyes J, Pokharna R, Mazariegos G, Green M, EghtesadB, Marsh W, Cacciarelli T, Fontes P, Abu-Elmagd K, Sindhi R, Demetris J, Fung J. Post-transplant lymphoproliferative disorders in liver transplantation: a 20-year experience. Ann Surg. 2002 Oct;236(4):429-36.

20. Wilde GE, Moore DJ, Bellah RD. Posttransplantation lymphoproliferative disorder in pediatric recipients of solid organ transplants: timing and location of disease. AJR Am J Roentgenol. 2005 Nov;185(5):1335-41.

21. Muti G, Cantoni S, Oreste P, Klersy C, Gini G, Rossi V, D’Avanzo G, Comoli P, Baldanti F, Montillo M, Nosari A, Morra E; Cooperative Study Group on PTLDs. Post-transplant lympoproliferative disorders: improved outcome after clinico-pathologically tailored treatment. Haematologica. 2002;87(1):67-77.

22. Bakker NA, van Imhoff GW, Verschuuren EA, van Son WJ, Homan van der Heide JJ, Veeger NJ, Kluin PM, Kluin-Nelemans HC. Early onset post-transplant lymphoproliferative disease is associated with allograft localization. Clin Transplant 2005 Jun;19(3):327-334.

23. Gerstenkorn C, Jackson G, Di Franco F, Thomusch O, Talbot D. Outcome of PTLD in renal and liver allograft recipients. Transplant Proc. 2001 Jun;33(4):2469-72.

24. Issa N, Amer H, Dean PG, Kremers WK, Kudva YC, Rostambeigi N, Cosio FG, Larson TS, Habermann TM, Stegall MD, Griffin MD. Posttransplant lymphoproliferative disorder following pancreas transplantation. Am J Transplant. 2009 Aug;9(8):1894902.

25. Lok C, Viseux V, Denoeux JP, Bagot M. Posttransplant cutaneous T-cell lymphomas. Crit Rev Oncol Hematol. 2005 Oct;56(1):137-45.

26. Morovic A, Jaffe ES, Raffeld M, Schrager JA. Metachronous EBV-associated B-cell and T-cell posttransplant lymphoproliferative disorders in a heart transplant recipient. Am J Surg Pathol. 2009 Jan;33(1):149-54.

27. Pitman SD, Huang Q, Zuppan CW, Rowsell EH, Cao JD, Berdeja JG, Weiss LM, Wang J. Hodgkin lymphomalike posttransplant lymphoproliferative disorder (HL-like PTLD) simulates monomor phic B-cell PTLD both clinically and pathologically. Am J Surg Pathol. 2006 Apr;30(4):470-6.

28. Timurağaoğlu A, Uğur-Bilgin A, Colak D, Tuncer M, Gölbaşi I, Hazar V, Kiliçarsłan B, Undar L, Demirbaş A. Posttransplant lymphoproliferative disorders in transplant recipients. Transplant Proc. 2006 Mar;38(2):641-5.

29. Abe T, Ichimaru N, Kokado Y, Maeda T, Kakuta Y, Okumi M, Imamura R, Nonomura N, Isaka Y, Takahara S, Okuyama A. Post-transplant lymphoproliferative disorder following renal transplantation: a single-center experience over 40 years. Int J Urol. 2010 Jan;17(1):4854.

30. Koukourgianni F, Harambat J, Ranchin B, Euvrard S, Bouvier R, Liutkus A, Cochat P. Malignancy incidence after renal transplantation in children: a 20-year singlecentre experience. Nephrol Dial Transplant. 2010 Feb;25(2):611-6.

31. Sandhu J, Dhiman A, Aulakh B, Sandhu P, Saggar K, Sood N, Khaira N. Post transplant malignancies - 8 cases observed in a single center. Indian $\mathrm{J}$ Nephrol. 2005; $15: 235-8$.

32. Bianchi E, Pascual M, Nicod M, Delaloye AB, Duchosal MA. Clinical usefulness of FDG-PET/CT scan imaging in the management of posttransplant lymphoproliferative disease. Transplantation. 2008 Mar 15;85(5):707-12.

33. Abramson JS, Kotton CN, Elias N, Sahani DV, Hasserjian RP. Case records of the Massachusetts General Hospital. Case 8-2008. A 33-year-old man with fever, abdominal pain, and pancytopenia after renal transplantation. NEngl J Med. 2008 Mar 13;358(11):117687.

34. Gallagher H, Kwan JT, Andrews PA. Posttransplantation lymphoproliferative disorder: an unusual 
presentation in a patient receiving tacrolimus. Nephrol Dial Transplant. 2000 Jun;15(6):928-30.

35. O'Conner AR, Franc BL. FDG PET imaging in the evaluation of posttransplant lymphoproliferative disorder following renal transplantation. Nucl Med Commun. 20056 Dec;26(12):1107-11.

36. Orjuela M, Gross TG, Cheung YK, Alobeid B, Morris E, Cairo MS. A pilot study of chemoimmunotherapy (cyclophosphamide, prednisone, and rituximab) in patients with post-transplant lymphoproliferative disorder following solid organ transplantation. Clin Cancer Res. 2003 Sep 1;9(10 Pt 2):3945S-52S.

37. Berg LC, Copenhaver CM, Morrison VA, Gruber SA, Dunn DL, Gajl-Peczalska K, Strickler JG. B-cell lymphoproliferative disorders in solid-organ transplant patients: detection of Epstein-Barr virus by in situ hybridization. Hum Pathol. 1992 Feb;23(2):159-63.

38. Benkerrou M, Durandy A, Fischer A. Therapy for transplant-related lymphoproliferative disease. Hematol Oncol Clin North Am. 1993 Apr;7(2):467-75.

39. Basgoz N, Preiksaitis JK. Post-transplant lymphoproliferative disorder. Infect Dis Clin North Am. 1995 Dec;9(4):901-23.
40. Walker RC, Paya CV, Marshall WF, Strickler JG, Wiesner RH, Velosa JA, Habermann TM, Daly RC, McGregor CG. Pretransplantation seronegative EpsteinBarr virus status is the primary risk factor for posttransplantation lymphoproliferative disorder in adult heart, lung, and other solid organ transplantations. J Heart Lung Transplant. 1995 Mar-Apr;14(2):214-21.

41. Ciancio G, Siquijor AP, Burke GW, Roth D, Cirocco R, Esquenazi V, Byrne GE Jr, Miller J. Post-transplant lymphoproliferative disease in kidney transplant patients in the new immunosuppressive era. Clin Transplant. 1997 Jun;11(3):243-9.

42. Mihalov ML, Gattuso P, Abraham K, Holmes EW, Reddy V. Incidence of post-transplant malignancy among 674 solid-organ-transplant recipients at a single center. Clin Transplant. 1996 Jun;10(3):248-55.

43. Nuckols JD, Baron PW, Stenzel TT, Olatidoye BA, Tuttle-NewhallJE, Clavien PA, Howell DN. The pathology of liver-localized post-transplant lymphoproliferative disease: a report of three cases and a review of the literature. Am J Surg Pathol. 2000;24(5):733-41. 